\title{
CRESCIMENTO E DESENVOLVIMENTO NA PRÁTICA DOS SERVIÇOS DE SAÚDE. REVISÃO HISTÓRICA DO CONCEITO DE CRIANÇA
}

\author{
Fabíola Zioni Gomes* \\ Rubens de C.F. Adorno*
}

ZIONI GOMES, F. \& ADORNO, R. de C.F. Crescimento e desenvolvimento na prática dos serviços de saúde. Revisão histórica do conceito de criança. Rev. Saúde públ., S. Paulo, 24: 204-11, 1990.

RESUMO: Discutem-se as condições para emergência e desenvolvimento de programas de saúde infantil. Discorre-se sobre o conceito da criança, saúde e serviços de saúde prevalente em determinados periodos históricos, assim como suas relaçōes com interesses político-econômicos dominantes nessas conjunturas, considerando-se os aspectos sociais do conhecimento.

DESCRITORES: Saúde pública, história. Saúde infantil. Serviços de saúde infantil, história.

Para se discutir o crescimento e desenvolvimento, enquanto prática de saúde pública, é necessário fazer alguns comentários sobre como se estruturam os serviços de saúde sobre o caráter social de sua formaçăo.

Já se pode considerar como clara entre os profissionais e estudiosos da área a existência de uma estreita relação entre saúde e sociedade, tanto no sentido da maneira como os homens vivem ser geradora da temática de saúde, como no sentido de que as intervençð̋es sobre ela săo determinadas socialmente.

Na identificação de problemas, na definição de suas causas, na elaboração de medidas terapêuticas ou preventivas e na definição de prazos e prioridades, outros elementos, além daqueles oriundos do conhecimento científico ou de normas racionais de conduta, são determinantes.

Entende-se por serviço de saúdc o exercício legitimado da medicina, odontologia e outras práticas de saúde pública, cujo fim explícito é preservar e restaurar a saúde da população (Singer ${ }^{10}$ ). Para o autor desta definiçăo, os serviços de saúde relacionam-se desde sua origem com a própria evolução do capitalismo industrial.

A revolução industrial - avanço tecnológico aplicado ao campo da produção - levou à substituição do trabalhador individual, manufatureiro e proprietário de seus instrumentos de trabalho, por unidades de produção baseadas no pleno aproveitamento da máquina e arregimentaçăo de quantidades cada vez maiores de mão-de-obra.

Esse grande contingente de trabalhadores pas- sou a viver em centros urbanos cuja precariedade exaustivamente descrita e analisada - levou ao incremento das doenças infecto-contagiosas que, por sua vez, passaram a significar entrave à expansão industrial.

Em decorrência disso surgiu a necessidade de criação de série de serviços - transporte, comunicação, saneamento do mcio e saúde - que pudessem controlar as relaçōes entre os indivíduos e o sistema social como um todo.

Nesse sentido, os serviços de saúde nascem e se desenvolvem com o intuito de produzir condiç̧es materiais e ideológicas indispensáveis ao desenrolar da vida política, social e econômica em determinados moldes. Assim, para cada conjuntura econômico-social de um país deve haver uma determinada organização dos serviços de saúde, adequada às necessidades de manter e reproduzir a força de trabalho e garantir a preservaçăo dessa estrutura.

Se a organização dos serviços de saúde é influenciada pela sociedade como um todo, é do conhecimento científico que ela vai tirar normas para sua atuação.

Vale lembrar que, se a ciência, entendida como um dos componentes do conhecimento humano, não pode ser considerada como desvinculada do momento histórico em que se dá esse conhecimento, assim ela também, a exemplo dos serviços de saúde, será afetada em sua organização e avanço por outras instâncias que não as do pensamento e reflexão.

Considerando-se, portanto, os dois problemas: a) características históricas, portanto político-

- Departamento de Prática de Saúde Pública da Faculdade de Saúde Pública da Universidade de São Paulo Av. Dr. Arnaldo, 715 - 01255 - São Paulo, SP - Brasil. 
ideológicas dos serviços de saúde; e b) complexidade dos fenômenos a serem tratados por eles (processo saúde-doença, processo crescimentodesenvolvimento, por exemplo), infere-se que o acompanhamento e controle deste último processo, em nível de políticas públicas e de programas específicos para o setor saúde, dificilmente poderá ser executado com desenvoltura suficiente.

A complexidade das questzes do crescimento e desenvolvimento pode ser considerada consensual entre os autores e profissionais da área.

No que se refere aos serviços de saúde, muitos elementos poderiam ser escolhidos para discussão. Selecionou-se, porém, uma questão espccífica, ou scja, comentar-se-á, no presente trabalho, como a criança é entendida pelos serviços de saúde e como esta compreensão é orientada pela conjuntura político-social, conferindo às propostas técnicocientíficas um conteúdo político-ideológico.

Escolheu-se este tema em função de se ter notado - já há algum tempo - um certo esvaziamento do debate político em torno da questão da saúde.

O debate sobre a determinação social do processo saúde-doença, sobre o direito à saúde como uma questão política e de extensão da cidadania, a tomada da questão da saúde pelos movimentos sociais urbanos constituíram-se traços importantes do setor ao longo dos anos 70 . Terminariam, porém, por serem absorvidos institucionalmente tanto em nível internacional (Alma-Ata, 1978) ${ }^{1}$ como em nivel nacional, principalmente depois da transição negociada.

No entanto, o debate acabou por se concentrar principalmente na organização de um Sistema Nacional de Saúde com as características necessárias para maior extensão e cobertura da população, fazendo com que problemas que extrapolam a assistência médica sejam tratados secundariamente.

Assim, discutir "crescimento e desenvolvimento" como um problema a ser assumido pelo setor saúde, dentro de uma perspectiva mais ainpla do que o acompanhamento antropométrico e a prevenção de doenças, pode ser oportuno no sentido de contribuir para a elaboração de um novo conceito de saúde e de saúde pública, para novas propostas práticas e políticas para o setor.

Para colaborar com este debate, acredita-se importante esclarecer como, em determinados momentos históricos, a sociedade reflctiu sobre a criança e como esta reflexão se traduziu $\mathrm{cm}$ termos de práticas sociais e/ou institucionais.

\section{A CRIANÇA: DO DESCOBRIMENTO À RUPTU- RA DO PACTO COLONIAL}

Até o século $\mathrm{XIX}$ não se registraram inter- venç̋es sistemáticas sobre a saúde da criança. No entanto, não deixaram de ocorrer reflexठes e práticas sobre ela e que diziam respeito ao tipo de conjuntura social em que eram elaboradas.

O período colonial por ser polarizado socialmente permite mostrar mais claramente esta relaçăo. Em termos gerais, o colonialismo pode ser entendido pelas palavras de Novais ${ }^{8}$ :

"Escravismo, tráfico negreiro, formas várias de servidăo formam portanto o eixo em torno do qual se estrutura a vida econômica e social do mundo ultramarino. A estrutura agrária fundada no latifúndio se vincula ao escravismo e através dele às linhas gerais do sistema; as grandes inversōes exigidas pela produção só encontram rentabilidade, efetivamente, se organizadas em grandes empresas".

Em síntese, a estrutura fundamental dos sistemas de colonização se traduzia em: latifúndio, escravidão e monocultura.

Esse tipo de organização social engendrava um padrão de relaçðes sociais caracterizado pelo autoritarismo e descompromisso social que, além de marcar toda a época colonial e diversas fases da História do Brasil, constitui-se, ainda hoje, um padrão significativo.

No que diz respeito à assistência médica, o Brasil-Colônia não registrava trabalhadores livres em número suficiente para justificar medidas de atendimento médico ou de saúde pública.

No Brasil, a grande massa de trabalhadores era constituída por escravos - considerados legalmente como coisas de propriedade do senhor rural. Não competia ao poder colonial zelar pela sua saúde.

A escassa população pobre, não-escrava, valiase de assistência filantrópica e religiosa.

Para as tropas militares existia a figura do Cirurgião-Mor que superintendia o exercício da cirurgia $\mathrm{c}$ dos hospitais militares. Ao Físico-Mor ou a seus delegados competia a supervisão do exercício da farmácia, da medicina, de curandeiros e de práticas de saneamento das cidades.

A questão da saúde, envolvendo uma preocupação com a assistência médica ou com a higiene das cidades, era subalterna ou inexistente; os problemas de higiene eram de responsabilidade das autoridades locais, que se limitavam a impedir a proliferação da imundície nas ruas e nos quintais.

Até meados do século XVIII a questão da saúde só se colocava a partir da simples percepção da relação entre "sujeira/cidade/doença", o que poderia prejudicar o comércio de produtos coloniais. 
No entanto, desde o século XVI as nações européias centrais, colocavam-se diante da questão da produtividade económica, que era entendida como relacionada à existência de uma população numerosa, crescente, sadia e plenamente empregada.

Essa preocupaçăo com a população não foi transportada para o Brasil, por vários motivos. Em primeiro lugar, pelo fato de essas preocupaçzes terem sido mais bem registradas na Alemanha, Inglaterra e França do que nos estados peninsulares. Em segundo lugar, a economia colonial organizava-se de forma suplementar à metróple. Esta deveria ser rica às expensas da colônia, que deveria produzir com um mínimo de investimento. Vale lembrar, ainda, que a mão-de-obra nas colônias era escrava, o que não justificava medidas de controle de saúde.

Nesse contexto explica-se a inexistência de uma política para crianças e/ou para o conjunto da população. A concepção de criança na colônia fica bem exemplificada pelo texto a seguir:

"Oh! Como estou feliz que morreu meu filho...

Quando eu morrer cinco criancinhas (estarăo) a me rodear.

Entra! Mamãe! (no paraíso)..."

Observando que essa reação era bastante comum na colônia, um viajante europeu assim se manifestou:

"Não posso ter uma opinião boa sobre o futuro de um lugar onde assim se dissolvem os mais fortes laços dos seres deste mundo". $\left(\right.$ Costa $\left.^{3}\right)$

Esta concepção de criança correspondia à forma de organização social engendrada pelo sistema colonial.

Assim como o indíviduo adulto não existia socialmente fora dos limites da propriedade rural (ou de sua extensão citadina), a criança só era vista como um elemento posto a serviço do poder paterno. Para a família, cujo "epicentro" repousava na figura paterna, a criança/filho só poderia receber uma atençăo genérica. Até o século XIX, a infância não foi tematizada, nem pela família nem pelo Estado. ${ }^{3}$

Este ponto pode ser explicado pelo fato de a estrutura social da Colônia ser polarizada entre proprietários e não-proprietários. A sobrevivência estava ligada à conquista e posse da propriedade, processo esse extremamente violento e dependente, em boa medida, da energia e capacidade do adulto-pai cuja figura não poderia ser desgastada, sequer em termos de desvio de atenç⿸丆es e/ou perda de prestígio.

Para reforçar essa concepção de criança, a tradiçāo católica concorria com a imagem de criança como ser purificado, sem mácula, um "anjo". Toda a preocupação iconográfica da época era coberta pela figura dos "anjinhos", cuja morte não seria motivo de dor, conforme dizia a canção: "Feliz anjinho que vai pro céu"3.

Essa tradição (que parece ter sido aproveitada pelos jesuítas para compensar a alta mortalidade de crianças indígenas na época) pode ter contribuído significativamente para que a vida biológico-moral da criança não fosse valorizada ${ }^{3}$.

Segundo Costa ${ }^{3}$, "na colônia a representação social da criança monopolizava o sentido de sua vida, os papéis culturais de 'filho incapaz' e de 'anjinho' superpunham-se e obscureciam sua condição de etapa biológico-moral no desenvolvimento do adulto.... Entre o adulto e a criança, as ligaçбes existentes eram as de propriedade $e$ da religião. Um fosso as separava. Os elos que uniriam a cadeia das geraçסes so foram criados quando a família dispôs de representaçōes da criança como matriz físico-emocional do adulto.... Esta recodificação da imagem da criança deveu-se em grande parte à reação dos higienistas".

Para o autor, a concepção colonial sobre família, crianças e mulheres fez com que até o século XIX não se registrasse preocupação com o crescimento e o desenvolvimento da criança. A criança como filho, elemento secundário da casa senhorial, não merecia maior destaque.

A família - ao contrário da visão ideal de família burguesa - não estava centrada no cuidado da prole: mesmo em nível de valores e princípios, explícitos ou não, a familia baseava-se na manutenção do patrimônio.

Neste contexto, as relaçőes pessoais e de afetividade não apareciam como centrais. $O$ caráter das relaçōes era dado pelo predomínio do pai, do adulto.

A partir de 1700 , a estrutura social começou a apresentar algumas trechas. Essas mudanças advinham da atividade mineradora, que requeria elementos livres, tanto da escravidăo como da propriedade rural e uma administração centralizada para controlar a produção, o que levava ao desenvolvimento dos primitivos núcleos urbanos.

No bojo dessas mudanças começava a surgir um novo elemento que seria a possibilidade de desenvolvimento do trabalho livre, cujo "locus" não seria o mundo da propriedade rural mas aquele da cidade colonial.

Pressupondo-se que a saúde pública aparece para atender questões que podem constituir barreiras ao desenvolvimento econômico, sua emergência no Brasil esteve relacionada à necessidade de controle do ambiente urbano, tanto no contexto das relações dos homens com o meio físico como no con- 
texto das relaçoes sociais que eram desenroladas dentro das condiçбes ditadas pelo modo de vida urbano, e deste urbano colonial com a Metrópole.

Principalmente a partir do século XVIII, com o surto da expansão urbana, a estratégia de dominaçăo da Metropole passou a enfatizar a segurança da cidade. Entre as várias estratégias elaboradas pelo Estado - militarizaçăo da população, controle urbano/sanitário, e outras, uma das que mais se destacou foi a questão da higienização da família.

Entende-se por higienização da famnlia, o processo relacionado à implantaçăo de uma visão de mundo para o conjunto da sociedade, visão essa necessária à manutenção do poder da Coroa Portuguesa (Estado), que fora relativamente contestado pelas elites coloniais cujos interesses năo mais coincidiam diretamente com aqueles das classes dominantes portuguesas.

Além disso, essas elites impunham às cidades - "locus" do poder metropolitano - uma lógica da propriedade rural, dado que a cidade era vista como extensão desta propriedade.

Ao trazer para a cidade o padrão de ocupaçăo do espaço e das relaçóes sociais do mundo rural, eram essas elites as grandes responsáveis pelo caos urbano que tanto ameaçava a colônia "...a anatomia urbana da Colônia mostra como a casa, ocupando todo o lote delimitava a rua, o privado impunha-se ao público que desembocava no desrespeito aos locais públicos, no descumprimento das normas de limpeza" (Costa $\left.{ }^{3}\right)$.'

- controle espacial pelas famílias proprietárias era reforçado pelo monopólio do poder. Apesar de amparar-se na própria legislaçăo municipal portuguesa, esse poder não correspondia mais às expectativas do Estado Português.

Em primeiro lugar, já não existia uma correspondência automática entre os interesses do latifúndio e da Metrópole. Em segundo, nos dizeres de Costa ${ }^{3}$, "a familia não formava cidadăos e sim parentes... a participação dos indivíduos nas sociedades resumia-se à defesa do grupo a que pertenciam... Donde a oposição que o Estado sofria quando os convocava para o cumprimento das tarefas nacionais..."

Não satisfeita em criar uma elite autocentrada e dependente do pai e do clă, a família colonial pretendia impor-se como modelo para o conjunto da sociedade: "...na medida em que dominava o meio urbano reduzia as outras camadas sociais a seu modo de ser..." 3 .

Esse padrão de comportamento em relação ao público precisou ser quebrado pela Coroa para manter a cidade livre da sujeira - que, pela criaçăo de doenças, perturbava as atividades comer- ciais - e da invasão de outras potências européias.

Para responder a essas contradiçóes, o Estado, entre outras estratégias, passou a intervir por meio da criação de uma visão de mundo que compatibilizasse as elites agrárias com seu projeto de dominação. Esta questão fica clara quando se analisa o discurso higienista que se afirmava, a partir do século XVIII, refletindo essa articulação entre medicina, saúde e sociedade em termos da criação de condiçőes superestruturais (ideológicas e políticas) para manutençăo da ordem.

O papel ideológico da medicina no sentido de moldar comportamentos compatíveis com o projeto econômico vigente era desenvolvido, naquele momento, em relação às famnlias da elite agrária, mas não se prendia à necessidade de resolver contradiçбes dadas em nível da estrutura de produção, mas à necessidade de adequar a tradição colonial dessas elites às novas exigências econômicas e políticas advindas com o fim do pacto colonial e com as transformaçōes que vinham ocorrendo na estrutura social brasileira. Esse processo exigiu uma ofensiva ideológica que foi travada principalmente pela estratégia higienista, cujo alvo principal foi a reestruturaçăo familiar, conforme a análise de Costa ${ }^{3}$. A reestruturação do núcleo familiar, por sua vez, implicava a mudança da concepção desenvolvida tradicionalmente sobra a criança.

Os cuidados gerais que a criança recebera durante todo o periodo colonial foram substituídos pela ação da higiene e da puericultura - por uma assistência sistematizada quanto a condutas alimentares, disciplinares, pedagógicas e mesmo de vestuário. Para desempenhar esses cuidados, a familia precisava redefinir o papel do pai e da mãe, precisava, principalmente, organizar-se em novos moldes.

Essa nova forma de organização familiar e o objetivo pelo qual ela passaria a se pautar (procriar e educar crianças sadias para a Nação carente de uma populaçăo forte e produtiva) eram compatíveis com a nova ordem que se pretendia instaurar a partir do século XIX: não mais uma Colônia voltada para interesses externos, não mais uma agregação de propriedades rurais regidas por interesses locais, mas uma Nação Independente, voltada para a produção e acumulação de capital.

Identificando o interesse do Estado com o interesse nacional e ambos a uma conduta entendida como "natural" e, portanto, desejável, a higiene passava a descrever o tipo de famillia e de educação necessários para a criação de um adulto identificado com a Nação/Estado.

Para Costa ${ }^{3}$, "a medicina social percebia que o processo de urbanização forçava a mudança da família e que o Estado, apoiando a expansão da 
saúde pública, lhe havia creditado uma certa confiança que competia explorar até onde fosse possível..." Citando autores da época, o autor afirma que a higiene era concebida como "a parte da ciência médica que nos dá os preceitos e as regras necessárias tanto à aquisiçăao como à conservação da saúde e se referem a exercícios, banhos, sono, paixбes, trabalhos intelectuais, enfim, ensina a evitar as coisas nocivas e fazer um bom uso das coisas úteis. Nada mais coerente com esta definição que a ingerência médica em todos os setores de vida pública e privada... Esse cuidado... tinha objetivos explícitos, dos quais o mais importante era a proteção das mulheres e crianças..."

No entanto - ainda que obedecendo a uma racionalidade científica mais avançada do que os paradigmas anteriores - a higiene e a medicina da época também estavam impregnadas pelo caráter social do conhecimento do qual nenhuma disciplina científica pode ser considerada isenta.

Nesse sentido, saúde em geral e a saúde da criança em particular começavam a se confirmar não só como um campo de intervenção técnica, mas como um campo de normatização da vida cotidiana, de acentuado caráter ideológico.

Pelas publicaçōes próprias e intenso debate teórico, os higienistas desenvolviam concepçōes sobre as relaçoes medicina/saúde e Estado que - a exemplo das propostas de higienização da família - eram imbuídos de conteúdo ideológico.

Conforme Machado e col. 5 ,

"Para que se preserve a saúde de uma população, portanto, há necessidade de implantação de uma sociedade onde não se suscitem paixzes, onde reine a ordem, onde tudo funcione... A medicina, conhecendo o homem e as alteraçōes de seu organismo provocadas pela desordem, deve guiar o processo de estabelecimento e o funcionamento desta sociedade... Oferece o saber do corpo, que deve ser disseminado por toda a sociedade - fazendo com que cada um evite a paixão e a desordem - e que deve ser a base do funcionamento do corpo social... Temperança, contingência, moderação nos costumes, tranquilidade da alma - virtudes que se opõcm à turbulência e desordem em defesa da vida, virtude cujo exercício é relacionado a uma sociedade que o permite, que o funde".

Viu-se, até aqui, como a concepção de criança esteve relacionada aos problemas que a socicdade colonial tinha que administrar.

\section{A CPIANÇA: DA CAFEICULTURA AO PROJETO INDUSTRIAL}

No final do século XIX, nas primeiras décadas do século $X X$, era outro o projeto dominante na sociedade brasileira.

A sociedade e o Estado viam-se às voltas com a criação e manutenção de condições para o desenvolvimento da cafeicultura, setor hegemônico na economia, o café consolidava no Estado uma oligarquia rural, para a qual a questão social era um "caso de polícia".

A saúde pública era entendida ou praticada como forma de garantir a produção e o escoamento do café. Daí as políticas de saneamento de portos e cidades próximas à cultura do café e/ou de combate às doenças que dificultassem a imigraçăo (febre amarela, varíola).

Acompanhando o processo de expansão do café, registravam-se a expansão urbana, o crescimerto populacional, as atividades comerciais e a crescente complexidade da sociedade brasileira.

Junto com os braços para o café vieram as idéias anarquistas que contribuiram para convulsionar 0 país. Em 1917, ocorria a maior greve do período. A Nação parava. O Estado, que reagia de maneira repressiva, foi, pouco a pouco, obrigado a mudar a concepção de problema social.

É nesse contexto que surgiram preocupaçōes mais sistematizadas com assistência às crianças, ainda marcadas, porém, por um conteúdo de controle social e decorrentes da necessidade de investir sobre a força de trabalho ou sobre as relações capitaltrabalho. Surgiram, também, os primeiros passos para a criação dos scrviços de saúde.

Em termos de serviços de saúde, datam de 1920 as primeiras preocupaçōes com o atendimento à criança, via serviço de higiene infantil; datavam também dessa época a regulamentação da licença à gestante e à pućrpera ( 30 dias para cada uma das situações) e a proibição do trabalho fabril para menores de 12 anos. A mortalidade infantil e a necessidade de atender a criança foram discutidos no Segundo Congresso Brasileiro de Proteção à Infância ${ }^{2}$.

Esses fatos mostram a emergência da questão das condições de vida e da saúde da criança no contexto da questão social, que já se configurava como problema do Estado Nacional ainda que com vestígios de "questão de polícia".

A preocupação com a higiene infantil inspirava-se no modelo médico-sanitário baseado na filosofia de saúde pública adotada nos EUA desde o sćculo anterior. Essa filosofia era voltada para o atendimento da população imigrante carente (dos EUA), com açōes de enfermagem domiciliária, prevençăo de tuberculose, tratamento de doenças venćreas e atendimento materno-infantil pelos Centros de Saúde e de Educação Sanitária, que vi- 
savam, de modo especial, a higiene individual, pré-natal, infantil e escolar, aproveitando a oportunidade apresentada pela infância para a implantação de hábitos sadios ${ }^{9}$.

Registrava-se, nessa época, o aparecimento concomitante da educação sanitária e da higiene infantil, ambas com a mesma orientação filosófica, que centrava no comportamento do indivíduo as raízes de seus problemas, sem refletir sobre as suas condiçōes concretas de existência, sobre o saber popular elaborado a respeito dos temas de saúde e sobre a estratégia de vida elaborada pelas camadas populares diante das pressóes do cotidiano.

A transmissão de informaçzes sobre higiene extrapolava a sua racionalidade interna à medida que englobavam afirmaçóes sobre comportamentos desejáveis do ponto de vista moral e que pretendiam desenvolver uma consciência cívica nacional, guardando uma semelhança temática com as propostas dos séculos XVIII e XIX em relação às elites da época, ainda que revestidas de maior "cientificidade" e orientadas para noldar o comportamento das classes populares urbanas agitadas pelos movimentos sociais dos anos 20 , pelas crises econômicas e pela fragilidade das políticas sociais que começavam a se desenvolver.

A proposta da educação sanitária justificava-se em termos de sua própria eficiência e lógica interna em relação à aquisição de saúde. Se não dava a idéia de uma identificação total entre higiene e moral, não deixava de relacionar conotaçōes moralistas e de propostas patrióticas ao comportamento esperado em saúde. Traziam também mensagens de conteúdo racista que não destoavam do ideário $€$ de paradigmas científicos da época.

Essas afirmaçס̃es são inferidas a partir da leitura de documentos e discursos da época. Na sessão inaugural do Segundo Congresso Brasilciro de Higiene ${ }^{2}$, realizado em 1928 , os congressistas manifestaram sua preocupação com a "torrente imigratória", com a "vaga nipônica" que, pela mistura das raças, poderia provocar o desaparecimento do "brasileiro vigoroso, rijo e capaz, consciente e culto" e convocou a saúde pública, pela ação de "enfermeiras visitadoras", para promover a educação nacional em tríplice aspecto físico, intelectual e moral, que promoveriam a "higienização das massas".

Resumindo, a saúde infantil, que emergia com as demais práticas sanitárias no bojo do processo de expansão capitalista, apesar de já se articular em termos de serviços de saúde e de utilizar algumas "armas" ierapêuticas científicas como vacinas, assistência pré-natal e puericultura, mantinha seu caráter ideológico quanto à constituição de uma visão de mundo adequada às elites dirigentes e assumia um papel cada vez mais importante nes- sa estratégia de controle, conforme relata Costa

"Durante os Congressos Brasileiros de Higiene, a questão da saúde infantil despertaria grande atenção". No entanto "...o objeto da reflexão não foi a condiçăo de vida e o trabalho da infância operária, como apareceu em alguns pontos da legislação sanitária. A reflexão... tendeu a privilegiar as disposiçóes da educação moralizadora e domesticadora. Ou seja, os sanitaristas elegeram a criança como alvo de intervenção pedagógica objetivando hábitos e atitudes da populaçăo frente à doença... A criança... seria o primeiro estágio da prática educacional em saúde cuja finalidade última seria atingir os padrőes sanitários familiares".

Não obstante seu caráter ideológico, as políticas públicas que diziam respeito às crianças representavam um avanço sobre suas anteriores condiçбes de vida e atenderam, de um lado, às exigências de preservar a força de trabalho e de regular as relaçues capital-trabalho e, de outro, às exigências do próprio movimento operário, conforme colocaçoes de Costa 4 .

Essas diretrizes não foram alteradas ao longo de todo o período histórico compreendido pelo Estado Novo (1937) e o Golpe de Estado de 1964, mesmo durante o breve período de democracia formal, populista, compreendido entre o pós-guerra e 1964. A criança foi tematizada ao longo desse período como uma peça na estratégia de poder por parte dos setores dominantes que, de um lado, precisavam criar um tipo de população afinada com os objetivos da sociedade e, de outro, precisavam garantir a reprodução da força de trabalho sem desviar recursos do projeto de industrialização. Engendrou-se, assim, uma política social de caráter restrito que se traduziu, em termos de saúde, pela baixa cobertura e atuaçăo normativa $e$ discursiva.

Em nivel do discurso, o Estado assumiu desde 1937 a responsabilidade pela saúde infantil. A saúde, por sua vez, era entendida a partir de características positivas e não como simples ausência de doenças. No entanto, segundo Novaes ${ }^{7}$, não se registrou nenhum efeito prático, "ainda era grave a realidade:... a mortalidade infantil ainda se apresenta em níveis bastante elevados, existe elevado grau de desorganização administrativa... a medicina, supondo-se que ela tenha papel a cumprir no controle das doenças, ainda está desarmada, não tem os antibióticos $e$ as vacinas".

As preocupações para com a criança, dentro do setor saúde, no entanto, independentemente de sua racionalidade interna, guardavam relações com propostas normativas de épocas anteriores (como as propostas higienicistas para a família), com a 
diferença de que eram voltadas para a criação de padrões adequados de comportamento junto às classes trabalhadoras, uma vez que a divergência entre as classes proprietárias rurais e o Estado havia se tornado secundária ou inexistente diante do desenvolvimento urbano-industrial e $o$ aparecimento de outras contradiçðes.

Administrar relaçðes conflituosas entre setores sociais, via atendimento de demandas e criação/ difusão de ideologia/visð̃es sociais de mundo, que justificassem a ordem reinante, foi um dos componentes da intervenção do Estado junto ao grupo infantil até 0 momento de ruptura do Estado Populista, nos meados da década de 60 .

Até 1964, as propostas para os grupos que se constituíam no interior do setor saúde, além de apresentarem essas características ideológicas, desenvolviam-se principalmente junto ao subsetor saúde pública que, a partir da década de 50 , passou paulatinamente para um lugar secundário com as preocupaçzes de expansão do atendimento médico via Previdência Social, expansão essa voltada para a mão de obra urbano-industrial.

A emergência de programas para crianças ${ }^{6}$ que se deu em meados da década de 70 configurava-se dentro de tentativas oficiais de racionalizar e implementar políticas sociais que legitimassem o Estado Militar em crise de sustentação política, encarregado de promover um projeto de desenvolvimento econômico caracterizado pcla concentração de riquezas e poder.

Uma vez apontadas as características políticoideológicas da emergência de programas para as crianças, agora entendidas como grupo maternoinfantil, delineiam-se outras indagaçōes: as recentes mudanças na conjuntura nacional, caracterizadas por uma transição negociada entre as cama- das dominantes, podem garantir a elaboração de propostas para o grupo que digam respeito às suas condiçōes concretas de vida? Os programas de saúde que se apresentaram a partir de meados da década de 80 foram elaborados com a participação dos setores da população para os quais são dirigidos? Representaram (e representam) uma opção política no sentido de garantir sua execução, a transparência de suas decisões e o controle desta execução pelos próprios interessados?

\section{CRIANÇA OU MENOR}

Concluindo, é importante relacionar dois momentos históricos que apresentam um ponto em comum extremamente dramático.

Se ao longo do período colonial não existia a criança, mas o filho, fosse o filho primeiro, herdeiro da propriedade, ou os demais, legítimos e/ou bastardos, que se enquadravam de maneira mais ou menos eficiente nos amplos limites do latifúndio, inclusive na sua extensâo citadina, qual o destino daqueles que não eram cobertos por esses limites?

Não se trata de um acaso histórico a instituição de "roda" como destino de quem não era filho da propriedade.

Se com o desenvolvimento econômico, com as mudanças sofridas pela sociedade brasileira o "filho da propriedade foi transformado em criança, o que aconteceu com o filho da "roda"?

Incapaz de "domesticar" ou atender via saúde ou educação os "filhos da roda", não terá a sociedade criado novamente dois tipos de concepção em relação à criança? De um lado a criança e de outro lado o menor?

Não será o "menor" o fruto deste descaso histórico com a criança?

ZIONI COMES, F. \& ADORNO, R. de C.F. [ Some considerations on growth and development in the practice of health services]. Rev. Saúde públ., S.Paulo, 24: 204 -11, 1990.

ABSTRACT: Conditions for the energence and development of health and social policy programs for children are discussed. The concepts of the child, health and health services prevalent in certain historical periods are expounded, as are the relationships of these proposals to the political and economic interest dominant in each social context, in the light of the social aspect of knowledge.

KEYWORDS: Public health, history. Child health. Child health services, history. 


\section{REFEREANCIAS BIBLIOGRÁFICAS}

1. CONFERENCIA INTERNACIONAL SOBRE CUIDADOS PRIMÁRIOS DE SAUDE, Alma-Ata, URSS, 1978. Relatorio. Brasilia, Unicef, 1979.

2. CONGRESSO BRASILEIRO DE HIGIENE, $2^{2}$, Rio de Janeiro, 1928. Anais. Rio de Janeiro, 1928.

3. COSTA, J.F. Ordem médica e norme familiar. Rio de Janeiro, Graal, 1979.

4. COSTA, N.R. Lueas urbanas e saúde pública. Petrópolis, Vozes, 1985.

5. MACHADO, R. et al. Danaçấo da norma: medicina social e constituiçäo de psiquiatria no Brasil. Rio de Janeiro, Graal, 1978.

6. MINISTERIO DA SAUDE. Programa materno.infantil. Brasflia, 1975.
7. NOVAES, M.H. A puericultura em questão. Săo Paulo, 1979. [Dissertação de Mestrado - Faculdade de Medicina da USP].

8. NOVAIS, F.A. O Brasil nos quadros do antigo sistema colonial. In: Mota, C.R., org. Brasil em perspectiva. Sto Paulo, Difel, 1976. p. 47-63.

9. ROCHA, S.M.M. Puericultura e enfermagem. Så Paulo, Cortez Ed., 1987.

10. SINGER, P. et al. Prevenir e curar: o controle social através dos serviços de saúde. Rio de Janeiro, Forense Universitária, 1979.

Recebido para publicaçdo em 1811011989

Reapresentado em 7/3/1990

Aprovado para publicaçáo em 9/3/90 